\title{
Electronic Markets on robotics
}

\author{
Rainer Alt ${ }^{1}$
}

Published online: 28 September 2021

(c) The Author(s) 2021, corrected publication 2022
This issue of Electronic Markets includes a comprehensive special issue section on artificial intelligence (AI) and robotics in travel, hospitality and leisure (THL). THL may be conceived as sub-sectors of the tourism industry, which Cook et al. (2018) compare to an elephant: "diverse and sometimes hard to describe, but, just like the elephant, too big to be ignored" (p. 6). Among the areas they mention are attractions and entertainment, food and beverage, accommodations, destinations, travel agencies and transportation. The information systems literature has recognized the elephant since many decades and Electronic Markets has published the first set of articles already in its second year of appearance, which dates back to 1992 . This special issue in volume two was on "electronic markets in the tourism industry" and included six (short) papers, while a second special issue on "electronic markets in tourism" with eight papers followed in 1996 and a third special issue on "smart tourism" with five papers in 2015. As shown in Table 1, the topics of most of these papers revolved around applying information systems for marketing, sales and distribution purposes in the respective sub-fields of tourism.

This is not surprising since the tasks related to the tourism areas primarily consist of information. In supporting coordination, the activities of marketing, sales and distribution are largely based on information and as already mentioned by Nicholas Negroponte in his seminal book "Being digital", substituting analog with digital information technologies has fundamental transformation power. Compared to atoms, bits will not wear out, they may be reproduced at zero cost and they move at light speed (Negroponte, 1995). Among the early examples that illustrate the implications on tourism are the computerized reservation systems (CRS) that spread from airlines to destinations, hotels or cars and changed the industry structures with new actors (e.g. CRS

Rainer Alt

rainer.alt@uni-leipzig.de

1 Information Systems Institute, Leipzig University, Grimmaische Str. 12, 04109 Leipzig, Germany spinoffs, online travel agencies) as well as new products and processes (e.g. self-booking, co-creation). At the same time, Negroponte mentions that "bits are not edible. In that sense, they cannot stop hunger" (Negroponte, 1995, p. 228). For tourism, this is obvious in the restaurant sector, where food will not be amenable to virtualization, but it also applies to many other sectors in tourism that comprise a physical component, such as accommodation or physical transportation.

\section{Hard and soft robots}

The relationship between the analog and digital representation of data is at the heart of the concept of digitalization (Alt, 2018) and the process of digital transformation. If analog formats are amenable to being digitized (e.g. pictures from a destination) or being substituted (e.g. physical boarding passes) by digital objects, the physical form may become obsolete. The miniaturization and networking of computing devices had a profound impact on providing, accessing and managing formerly analog data almost anytime from anywhere. Where the physical objects could not be virtualized, computing devices were infused (or attached), which linked them to the virtual world. While the term cyber-physical systems (CPS) reflected this link rather properly, the often synonymously used term of smart products suggested that the products also assumed some form of intelligence. This is reflected in the papers on smart mobility (see rows Vol. 29 and Vol. 31 in Table 1), which included algorithms from artificial intelligence (AI) and approaches from collective intelligence. Some of these articles were part of Electronic Markets' special issue on smart services, which also comprised a paper on smart service systems that mentioned robots in automotive manufacturing as one form of smart products (Beverungen et al., 2019).

Remarkably, another search among the Electronic Markets papers in the Springer Link database revealed that the notion of robots is mentioned in 29 papers (as of August 24,2021 ) and that most hits were either online first papers or research that referred to software robots. One example 
Table 1 Coverage of tourism topics in Electronic Markets (GR: general research, SI: special issue, *: tourism SI)

\begin{tabular}{|c|c|}
\hline Issue & Title of article \\
\hline Vol. 2 (1992), SI (in German)* & $\begin{array}{l}\text { - Electronic reservation systems } \\
\text { - The multimedia-tourist information system SI-TOUR } \\
\text { - Computer-based travel distribution systems and their interorganizational implications } \\
\text { - TIS- the Tirol information system } \\
\text { - EUROTOP - a European project to develop the electronic travel catalog } \\
\text { - TRAVISWISS - New paths in sales and distribution }\end{array}$ \\
\hline Vol. 5 (1995), GR & $\begin{array}{l}\text { - The emergence of electronic market systems in the European tour operator business } \\
\text { - Electronic markets in tourism-constraints and opportunities }\end{array}$ \\
\hline Vol. 6 (1996), SI* & $\begin{array}{l}\text { - Enhancing the competitiveness of small and medium-sized tourism enterprises } \\
\text { - Beyond Viewdata } \\
\text { - User-driven applications of advanced networks for electronic marketing of tourism products } \\
\text { - TIM and SAM-use of technology to create new business relationships for tourism } \\
\text { - EURO-LOG: a system for IT-based logistic integration } \\
\text { - Jerseylink: the island of Jersey central reservations system } \\
\text { - Info Austria / Eurostart Austria: The All-Austrian tourism information and reservation system }\end{array}$ \\
\hline Vol. 6 (1996), GR & - The four global distribution systems in the travel and tourism industry \\
\hline Vol. 7 (1997), GR & $\begin{array}{l}\text { - The main national travel and tourism distribution systems in Britain and Germany } \\
\text { - Gulliver-distributing Irish tourism electronically }\end{array}$ \\
\hline Vol. 8 (1998), GR & $\begin{array}{l}\text { - Distribution of Danish tourism products in Europe-status, trends and challenges } \\
\text { - Re-engineering travel agencies with the world wide web }\end{array}$ \\
\hline Vol. 9 (1999), GR & $\begin{array}{l}\text { - Electronic markets in transport: comparing the globalization of air and rail computerized reservation systems } \\
\text { - ICT and the changing landscape of global tourism distribution }\end{array}$ \\
\hline Vol. 10 (2000), GR & - Destination Maui? An exploratory assessment of the efficacy of self-booking in travel \\
\hline Vol. 12 (2002), GR & - Consumer attitudes and mobile travel portal \\
\hline Vol. 13 (2003), GR & $\begin{array}{l}\text { - Assessing motivation of contribution in online communities: an empirical investigation of an online travel } \\
\text { community } \\
\text { - Emerging pricing strategies on the web: lessons from the airline industry }\end{array}$ \\
\hline Vol. 17 (2007), GR & - Tourism and travel electronic commerce in China \\
\hline Vol. 19 (2009), GR & - Designing for reintermediation in the brick-and-mortar world: towards the travel agency of the future \\
\hline Vol. 24 (2014), GR & $\begin{array}{l}\text { - Designing for mobile value co-creation-the case of travel counselling } \\
\text { - A service innovation evaluation framework for tourism e-commerce in China based on BP neural network }\end{array}$ \\
\hline Vol. 25 (2015), SI* & $\begin{array}{l}\text { - Smart tourism: foundations and developments } \\
\text { - The application and impact of gamification funware on trip planning and experiences: the case of TripAdvi- } \\
\text { sor's funware } \\
\text { - How does hotel attribute importance vary among different travelers? An exploratory case study based on a } \\
\text { conjoint analysis } \\
\text { - Mineable or messy? Assessing the quality of macro-level tourism information derived from social media } \\
\text { - Smart technologies for personalized experiences: a case study in the hospitality domain }\end{array}$ \\
\hline Vol. 29 (2019), SI & $\begin{array}{l}\text { - User preferences and willingness to pay for in-vehicle assistance } \\
\text { - Enabling crowdsensing-based road condition monitoring service by intermediary }\end{array}$ \\
\hline Vol. 31 (2021), GR & - Smart mobility - an analysis of potential customers' preference structures \\
\hline
\end{tabular}

of the latter is the fundamentals paper on robotic process automation (RPA) by Hofmann et al. (2020), which conceives software robots as technological modules that "automate processes originally operated by human work" (p. 99) and expects them to become more intelligent by adopting AI technologies. Other contributions in Electronic Markets referred to robots as bots that support the interaction between humans and application systems (e.g. Stoeckli et al., 2020). This software side of robotics complements the view whereas robots are physical in nature and is reflected in the definition whereas robots are "physical and virtual technologies that engage in embodied actions" (Robert, 2018). In addition, Matarić (2007, p. 1) points at the Czech origins of the term robot, which emerged as a combination of "rabota" for "obligatory work" and "robotnik" for "serf". Robotics may thus be conceived as an interdisciplinary field that comprises two forms of automation to perform activities, which are similar to or formerly performed by humans:

- Physical robots ("hard robots") have seen large progress in the field of manufacturing and much research is available from the engineering sciences where concepts such as Industry 4.0 foresee a high degree of integration and interaction between physical robots. More recently, 
robots have appeared in service industries like healthcare, transportation or banking. For example, financial service providers have conducted experiments with Softbank Robotics' "Pepper" robot for customer interaction in branch offices, hospitals with Intouch's "Vita" robot for patient interaction and logistics companies with Boston Dynamics' "Atlas" robot for goods handling in warehouses.

- Virtual robots ("soft robots") in contrast were rather driven by computer science and information systems disciplines. These robots execute one or more automation artifacts (e.g. a business process) sequentially or simultaneously and may be rather static in nature (e.g. when transferring data between systems like in RPA) or feature higher levels of autonomy when equipped with AI (e.g. a robo-advisor that autonomously orders and restructures portfolios). Soft robots have seen adoption in financial service companies for automating advisory and backoffice tasks, but also in healthcare for advising patients and doctors.

Obviously, hard and soft robots are not mutual exclusive categories. In fact, like each computing system, the hardware of a physical robot will also require a software component for activating and controling the hardware functions. If, for example, the humaniod Pepper advisor in a bank offers financial advice, it might also include or have access to a robo-advisor soft robot. Similarly, the autonomously driving vehicles or the recently presented humanoid robot from Tesla rely on a close combination with AI systems (Elliot 2021).

\section{Autonomy and digital twins}

In particular, hard robots have appeared early on in many science fiction novels and come with scenarios where these machines take over and dominate humans. This might be largely due to the close link with autonomous behavior, which is regarded as a key characteristic of robots. Following the definition of (Matarić 2007), a robot "acts on the basis on its own decisions, and is not controlled by a human" (p. 2). However, similar to the associated notion of intelligence, the requirement of autonomy has been debated by many researchers. In fact, most of today's physical and virtual robots will neither comply with such complete independence from human control nor is it clear whether this high level of full autonomy would actually be a desired state. The idea of an "autonomy continuum" has therefore been suggested, which conceives autonomy to exist in many forms on a continuum ranging from no autonomy to full autonomy and relates autonomy to the application purpose (Beer et al., 2014). While in standardized routine environments largely deterministic rule-based systems like RPA might be appropriate, robots with more adaptive skills based on stochastic reasoning might be required for higher complex tasks. A critical ingredient for attaining advanced levels of autonomy is AI, in particular the capabilities in learning and adaptive behavior, which depend on the respective algorithms and - even more important - on the inclusion of additional data. Although these may be included in a soft robot system, adding another (cyber) layer (see Aheleroff et al., 2021) for monitoring the system and for coordinating its interaction with other systems has emerged with the concept of digital twins. With origins in the field of manufacturing, a "twin" was seen as a digital model or replica of a physical asset that could then be simulated and improved more easily. For example, crash tests of a vehicle's digital twin could be performed much more efficiently than with the physical counterparts. In this sense Barricelli et al., (2019, p. 167, 656) define digital twins "as (physical and/or virtual) machines or computerbased models that are simulating, emulating, mirroring, or "twinning" the life of a physical entity, which may be an object, a process, a human, or a human-related feature."

Today, the digital twin concept has spread across many application domains, such as cities, health, energy, airports, transportation, logistics or agriculture (Kim et al., 2021, p. 10). Similar to the autonomy continuum, Kim et al. (2021, p. 62) distinguish five levels of maturity for digital twins, which reach from mirroring, monitoring, modeling and simulation to federated and autonomous. While they mention examples for the first three maturity levels (i.e., monitoring, modeling and simulation), the higher levels of federated as well as of autonomous twins are still considered fields for future research without existing implementations. They also confirm a growing application of digital twins in service industries, where the maturity is assessed as being lower compared to manufacturing industries. This might be related to the immaterial nature of services since a digital twin would then refer to the representation in the software itself, i.e. a customer profile in a customer relationship management system or the booking status and capacity utilization in a reservation system. However, compared to an application system, a digital twin is more specific and would represent resources in these systems (e.g. a customer, a hotel or restaurant location, a transportation vehicle). In addition, digital twins have been suggested for soft robots. For example, in the field of RPA the digital twin concept was proposed for development and testing purposes. As "a virtual shadow of an IT system" the twin "allows developing RPA externally without having access to the real system." (Wewerka \& Reichert, 2020, p. 12). Digital twins would then complement the software robots and contribute a certain (more advanced) level of autonomy. Two areas should be mentioned:

- Customer empowerment. Robotics in the form of digital twins could enable a move towards stronger customer- 


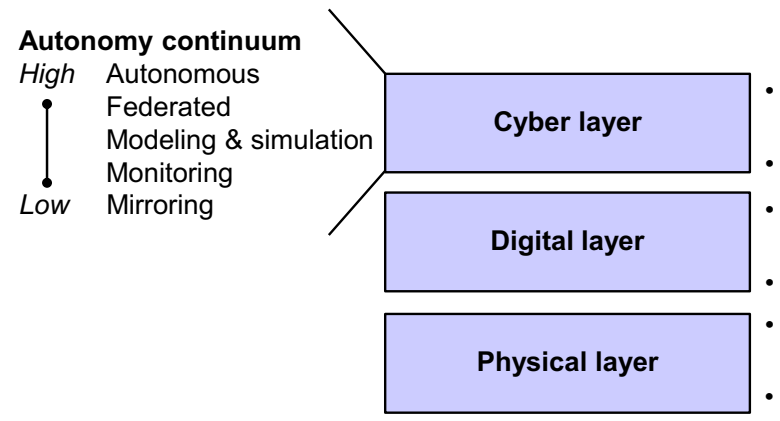

Digital replica systems for adding coordination and simulation functionalities ("digital twins")

Examples: Digital shadows, digital identities, autonomous twins

Application systems that include information on physical layer devices ("soft robots")

Examples: Booking and reservation, recommendation, tracking systems Physical resources with sensors, actuators, information processing skills ("hard robots")

Examples: CPS, humanoid robots, self-driving vehicles

Fig. 1 Layers for robotics (based on Aheleroff et al., 2021 and Kim et al. 2021)

induced service orchestration and control. As mentioned in an Electronic Markets position paper (Alt et al., 2019), service customers in many industries are confronted with information asymmetries with regard to service providers and intermediaries. For example, travelers still lack support when configuring more complex service bundles or when changes during service production occur, e.g. a flight is delayed and the connecting journey needs to be rescheduled. Similarly, the patient pathway in healthcare typically involves multiple service providers and patients often lack the transparency on the overall course of the treatment (see Alt \& Zimmermann, 2021). Instead of agents that act on behalf of a principal, twins would rather be close representations of the principals themselves. They could support travelers and patients alike in becoming empowered. Examples towards such a self-determined life of citizens are robots in the form of a digital shadow for monitoring activities and data, a digital me (or identity) for supporting standard decisions and a personal digital twin that takes over certain activities (Meister \& Otto, 2019).

- Resource coordination. As an industry with virtual and physical elements, tourism will require the interaction of several resources, in particular, locations, employees and devices such as vehicles or kitchen equipment. On the one hand, autonomy might be added to these resources, which is based on the abilities of hardware robots to provide the necessary skills to collect data and fulfill the required actions (e.g., autonomous vehicles, cooking robots or receptionist vehicles). Similar to the customer side, autonomy could come with digital shadows for monitoring and sharing status data with other resources as well as with (pro)active functionalities to automate standard coordination activities for replenishment or availability requests. Digital twins could also take over more complex negotiations in decentralized autonomous coordination scenarios. While this resembles the customer side, a major difference of interactions among service providers will be that digital twins are complementing existing applica- tion systems for master data, bookings or recommendations (see Fig. 1). On the other hand, digitalization could help in virtualizing physical elements in tourism. This could apply to moving meetings or events to virtual spaces like videoconferences or even virtual reality "metaverses" where digital twins meet.

\section{Implications}

Obviously, these two areas illustrate the potential of robotics and AI for the field of tourism. For a journal like Electronic Markets, this represents a broad and interdisciplinary field of research between engineering (e.g. for physical robots), computer science (e.g. for AI), information systems (e.g. for inter-robot coordination) and also psychology (e.g. for human-machine interaction). Three implications shall be addressed:

- First, the field of robotics promises potentials for the actors in networked business. For customers, robots might pave the way towards a broader coverage of entire customer journeys. Since these journeys typically include multiple actors, customers (or in other roles as patients or citizens) are often left alone in configuring and especially in reconfiguring their service bundles. Much like the robo-advisors in the finance domain, digital twins could become "guiding angels" that serve individuals in coordinating and restructuring their service portfolio - a task that will especially prove valuable in time-critical situations (e.g. a missed connecting flight, a critical chief complaint in medicine). On the provider side, robots have been applied in digital platforms early on. In a general form, the functionality of search engine relies on robots that automatically crawl web presences and compile the results. Similarly, in an effort to improve market transparency, price search and comparison agents were developed such as Bargain Finder or Auction Bot and gave rise to intermediaries for product brokering, merchant brokering as well as for negotiation (Guttman et al. 1999). In the same vein, intermediaries and providers could use 
these robots not only in monitoring their operations, but also in offering self-service for goods with an increasing complexity in their product descriptions and in automating customer service interactions. Finding the appropriate balance between machine and human interactions in hybrid solutions that offer sufficient "human touch" will be challenging here.

- Second, the interaction of robots on digital platforms will bring new challenges. It may be expected that once physical and virtual resources alike possess a digital twin representation, much coordination among service providers will become automated. It might follow a path that has become visible with algorithmic trading in the area of financial exchanges where software robots autonomously (or within defined limits) initiate buy and sell orders. Among the developments were high-frequency trading strategies that aim at achieving small arbitrage with short holding periods as well as various forms of strategic behavior. An example are countermeasures to robotic behavior such as manual confirmations on statements such as "I am not a robot". It stems from the perception that transparency will not be in every actor's interest and lead providers to avoid being crawled. In addition, the financial markets have shown that the dynamics of interactions between robots might generate undesired states on electronic markets with flash crashes being among the most well-known effects. Another possibility is algorithmic collusion that refers to unexpected consequences when AI systems learn autonomously (Calvano et al., 2020).

- Third, new forms of digital platforms are expected to emerge for robotics. This implication follows the last Electronic Markets editorial (Alt, 2021a), which recognized "AI platforms" as a specific form of digital platforms. An example in the context of robots is IBM's "digital twin exchange", which aims at establishing an ecosystem for trading digital twins (see https://www.ibm. com/products/digital-twin-exchange). An accompanying "digital twin kitt" tool in the Watson Assistant development environment supports developers in creating these digital twins.

In summary, it may be assumed that robots take over many tasks from human actors and open a broad spectrum of design options - from networked business, to applications in digital platforms and dedicated digital platforms. Although they will not replace many physical parts in service industries such as tourism, they may be expected to increase customer experience and resource coordination. While it should be clear that machines should always serve human actors, the varying interests of actors in economic and social life will also lead to different robotic behavior. Thus, rules and governance of these systems will become an important issue in the future besides the implications on industry, business processes and information systems. In any case, the field of robotics and AI should not be limited to technical design issues. This established insight is emphasized in an interview with Yao-Hua Tan from Delft University that is included in the present issue (Alt, 2021b). Based on observations from several large applied AI projects, it emphasizes the need for domain experts to be involved early on in AI projects and not to consider AI projects as purely technological projects.

\section{Articles of present issue}

Besides the interview, the present issue includes a total of 13 papers with eight belonging to the special issue on AI and robotics in the THL field. These contributions address several issues of robotics that were mentioned above and will be introduced in the separate preface, which was authored by the guest editors Chulmo Koo, Zheng Xiang, Ulrike Gretzel, and Marianna Sigala (Koo et al., 2021). They see the post-pandemic THL industry on the verge of important transformations that affect both customer as well as provider interaction and also call for more multidisciplinary research. Many thanks go to the guest editors' team, the authors and the reviewers, who dedicated much effort in making this special issue possible. In particular, we are grateful that Ulrike Gretzel also agreed to join Electronic Markets' team of associate editors!

In the general research section of this issue, the first paper presents a comprehensive literature review on the adoption of machine learning methods in information systems research. Based on their analysis of top-ranking journals, the authors Benjamin M. Abdel-Karim, Nicolas Pfeuffer and Oliver Hinz observe a reluctance of applying machine learning methods within information systems publications and call for "bridging the gap between the data-driven and the theory-driven research models" (Abdel-Karim et al., 2021). They expect that this could generate benefits for both sides, i.e. machine learning could enhance the body of knowledge on their use in organizations and society and information systems theories could contribute to applying machine learning in diverse industrial settings.

The second general research paper follows the recommendation of Abdel-Karim et al. and adopts the k-nearest neighbor algorithm, which belongs to the field of shallow machine learning to predict whether crowdfunding project campaigns will be successful. Titled "Feature subset selection for predicting the success of crowdfunding project campaigns" Michael Joseph Ryoba was successful in identifying nine features that positively impact the success of project campaigns on such digital platforms (Ryoba, 2021). Among these features obtained from an experiment based on 
Kickstarter data, are the project description length as well as the number of videos, updates, reward words, past projects, and comments.

The third paper is a fundamentals paper and presents an overview and introduction of the machine learning concept as a key area of AI (Janiesch et al., 2021). Besides categorizing shallow and deep learning algorithms, it emphasizes deep learning since the approach has spread in the field of intelligent systems for electronic markets and networked business in general. The authors present four challenges in the context of electronic markets that reflect potentials for new markets and ecosystems as well as risks that need to be addressed, such as avoiding adversarial attacks or dealing with the problems of drift and bias.

The fourth paper is another application of machine learning and aims at predicting early purchase intentions in online session-based retailing systems (Esmeli et al., 2021). It recognizes the preference of users to remain anonymous when comparing offerings and after a session has ended. In their experiments the authors Ramazan Esmeli, Mohamed BaderEl-Den and Hassana Abdullahi used five machine learning models and showed that users who are attributed a higher probability of intending a purchase, incentives could be offered in real-time, i.e. during a session. The underlying conceptual early purchase prediction framework is suggested as an enhancement to existing recommender systems.

The final paper investigates the autocomplete functionality that is visible in many websites when users enter a keyword and the systems completes these characters with possible (full) keywords. Contrary to existing research, the authors Eran and Amir Rubin focus on the diversion effect, which takes place if the proposed keyword diverts users from their initially intended search (Rubin \& Rubin, 2021). Using data from new securities in financial markets, an econometric model is proposed and aims to measure the economic effects of the text completion interface. It reveals significant impact of the choice of tickers (i.e. the acronyms of a security), which following the results of the research, should have more similarity to other tickers in the market.

Funding Open Access funding enabled and organized by Projekt DEAL.

Open Access This article is licensed under a Creative Commons Attribution 4.0 International License, which permits use, sharing, adaptation, distribution and reproduction in any medium or format, as long as you give appropriate credit to the original author(s) and the source, provide a link to the Creative Commons licence, and indicate if changes were made. The images or other third party material in this article are included in the article's Creative Commons licence, unless indicated otherwise in a credit line to the material. If material is not included in the article's Creative Commons licence and your intended use is not permitted by statutory regulation or exceeds the permitted use, you will need to obtain permission directly from the copyright holder. To view a copy of this licence, visit http://creativecommons.org/licenses/by/4.0/.

\section{References}

Abdel-Karim, B.M., Pfeuffer, N., \& Hinz, O. (2021). Machine learning in information systems - a bibliographic review and open research issues. Electronic Markets, 31(3). https://doi.org/10. 1007/s12525-021-00459-2.

Aheleroff, S., Xu, X., Zhong, R. Y., \& Lu, Y. (2021). Digital twin as a service (DTaaS) in industry 4.0: an architecture reference model. Advanced Engineering Informatics, 47, 101225. https://doi.org/ 10.1016/j.aei.2020.101225.

Alt, R. (2018). Electronic Markets on digitalization. Electronic Markets, 28(4), 397-402. https://doi.org/10.1007/s12525-018-0320-7.

Alt, R. \& Zimmermann, H.-D. (2021) The digital transformation of healthcare - An interview with Werner Dorfmeister. Electronic Markets (2021). https://doi.org/10.1007/s12525-021-00476-1.

Alt, R. (2021a). Electronic Markets on digital platforms and AI. Electronic Markets, 31(2), 233-241.https://doi.org/10.1007/ s12525-021-00489-w.

Alt, R. (2021b). How to organize for AI? An interview with YaoHua Tan. Electronic Markets, 31(3). https://doi.org/10.1007/ s12525-021-00497-w.

Alt, R., Ehmke, J. F., Haux, R., Henke, T., Mattfeld, D. C., Oberweis, A., Paech, B., \& Winter, A. (2019). Towards customer-induced service orchestration - requirements for the next step of customer orientation. Electronic Markets, 29(1), 79-91. https://doi.org/10. 1007/s12525-019-00340-3.

Barricelli, B. R., Casiraghi, E., \& Fogli, D. (2019). A survey on digital twin: Definitions, characteristics, applications, and design implications. IEEE Access, 7, 167653-167671. https://doi.org/10.1109/ ACCESS.2019.2953499.

Beer, J. M., Fisk, A. D., \& Rogers, W. A. (2014). Toward a framework for levels of robot autonomy in human-robot interaction. Journal of Human-Robot Interaction, 3(2), 74-99. https://doi.org/10.5898/ JHRI.3.2.Beer.

Beverungen, D., Müller, O., Matzner, M., Mendling, J., \& vom Brocke, J. (2019). Conceptualizing smart service systems. Electronic Markets, 29(1), 7-18. https://doi.org/10.1007/s12525-017-0270-5.

Calvano, E., Calzolari, G., Denicolò, V., Harrington, J. E., Jr., \& Pastorello, S. (2020). Protecting consumers from collusive prices due to AI. Science, 370(6520), 1040-1042. https://doi.org/10.1126/ science.abe 3796.

Cook, R. A., Hsu, C. H. C., \& Taylor, L. L. (2018). Tourism: The business of hospitality and travel (6th ed.). Pearson, Harlow.

Elliott, R. (2021). Elon Musk doubles down on artificial intelligence at Tesla amid scrutiny of autopilot. Wall Street Journal, August 20.

Esmeli, R., Bader-El-Den, M., \& Abdullahi, H. (2021). Towards early purchase intention prediction in online session based retailing systems. Electronic Markets, 31(3). https://doi.org/10.1007/ s12525-020-00448-x.

Gretzel, U., Koo, C., Sigala, M., \& Xiang, Z. (2015). Special issue on smart tourism: convergence of information technologies, experiences, and theories. Electronic Markets, 25(3), 175-177. https:// doi.org/10.1007/s12525-015-0194-X.

Gretzel, U., Sigala, M., Xiang, Z., \& Koo, C. (2015b). Smart tourism: Foundations and developments. Electronic Markets, 25(3), 179-188. https://doi.org/10.1007/s12525-015-0196-8.

Guttman, R., Moukas, A., \& Maes, P. (1999). Agents as mediators in electronic commerce. In: Klusch, M. (ed). Intelligent information agents. Springer, Berlin, Heidelberg (pp. 131-152). https://doi.org/ 10.1007/978-3-642-60018-0_8.

Hofmann, P., Samp, C., \& Urbach, N. (2020). Robotic process automation. Electronic Markets, 30(1), 99-106. https://doi.org/10.1007/ s12525-019-00365-8. 
Hunt, J. D., \& Layne, D. (1991). Evolution of travel and tourism terminology and definitions. Journal of Travel Research, 29(4), 7-11. https://doi.org/10.1177/004728759102900402.

Janiesch, C., Zschech, P., \& Heinrich, K. (2021). Machine learning and deep learning. Electronic Markets, 31(3). https://doi.org/10.1007/ s12525-021-00475-2.

Kim, Y.-W., Yoo, S., Lee, H., \& Han, S. (2021). Characterization of digital twin. Technical Report. https://www.researchgate.net/publi cation/353930234_Characterization_of_Digital_Twin, Accessed 23 August 2021.

Koo, C., Xiang, Z., Gretzel, U., \& Sigala, M. (2021). Artificial intelligence (AI) and robotics in travel, hospitality and leisure. Electronic Markets, 31(3). https://doi.org/10.1007/ s12525-021-00494-z.

Matarić, M. J. (2007). The robotics primer. MIT Press, Cambridge.

Meister, S., \& Otto, B. (2019). Digital life journey - framework for a self-determined life of citizens in an increasingly digitized world. Fraunhofer Institute for Software and Systems Engineering ISST. Dortmund. https://doi.org/10.24406/ISST-N-559377.

Negroponte, N. (1995). Being digital. Alfred A. Knopf, New York.

Robert, L.P. Jr. (2018). Personality in the human robot interaction literature: a review and brief critique. Proceedings of the $24^{\text {th }}$
Americas Conference on Information Systems, New Orleans. https://ssrn.com/abstract=3308191, Accessed 23 August 2021.

Rubin, E., \& Rubin, A. (2021). On the economic effects of the text completion interface: empirical analysis of financial markets. Electronic Markets, 31(3). https://doi.org/10.1007/ s12525-021-00485-0.

Ryoba, M.J. (2021). Feature subset sel ection for predicting the success of crowdfunding project campaigns. Electronic Markets, 31(3). https://doi.org/10.1007/s12525-020-00398-4.

Stoeckli, E., Dremel, C., Uebernickel, F., \& Brenner, W. (2020). How affordances of chatbots cross the chasm between social and traditional enterprise systems. Electronic Markets, 30(2), 369-403. https://doi.org/10.1007/s12525-019-00359-6.

Wewerka, J., \& Reichert, M. (2020). Robotic process automation - a systematic literature review and assessment framework. https:// arxiv.org/pdf/2012.11951.pdf, Accessed 27 August 2021.

Publisher's Note Springer Nature remains neutral with regard to jurisdictional claims in published maps and institutional affiliations. 